九州大学学術情報リポジトリ

Kyushu University Institutional Repository

\title{
Effect of Fuel Orientation on the Performance of Air Curtains in Confining Fire and Smoke Propagation in Informal Shopping Malls
}

\section{Md Arif Mahmud Shuklo Shoshe}

Department of Mechanical and Production Engineering, Ahsanullah University of Science and Technology

Md. Ashiqur Rahman

Department of Mechanical Engineering, Bangladesh University of Engineering and Technology

https://doi.org/10.5109/4102503

出版情報: Proceedings of International Exchange and Innovation Conference on Engineering \& Sciences (IEICES). 6, pp. 277-283, 2020-10-22. Interdisciplinary Graduate School of Engineering Sciences, Kyushu University バージョン：

権利関係 : 


\title{
Effect of Fuel Orientation on the Performance of Air Curtains in Confining Fire and Smoke Propagation in Informal Shopping Malls
}

\author{
Md Arif Mahmud Shuklo Shoshe ${ }^{1}$, Md. Ashiqur Rahman²* \\ ${ }^{1}$ Department of Mechanical and Production Engineering, Ahsanullah University of Science and Technology, Dhaka- \\ 1208, Bangladesh, \\ ${ }^{2}$ Department of Mechanical Engineering, Bangladesh University of Engineering and Technology, Dhaka-1000, \\ Bangladesh. \\ *Corresponding author email: ashiqurrahman@me.buet.ac.bd, ashiqur78@yahoo.com
}

\begin{abstract}
The effect of fuel orientation on air curtain performance in confining fire and smoke in case of a clothing store fire in typical informal shopping malls of Bangladesh is examined numerically. Three fuel packages of different density and three types of fuel distributions are analyzed using Fire Dynamics Simulator (FDS). Fire and smoke spread, temperature and carbon monoxide concentration at critical locations and effectiveness of air curtain are analyzed from evacuation perspective to obtain a safer storage and arrangement of clothing fuels. Dependency of fire behavior and air curtain jet interaction on fuel density, fuel distribution and storage height are observed. The time required for flame spread from the source store to the hallway is reduced by at least 50s when air curtain is discharged for 'Grid'type fuel distribution compared to other orientations. This indicates a significant increase in the safe evacuation time in case of air curtains compared to the no curtain and actual fuel distribution cases.
\end{abstract}

Keywords: Fire Safety; Air Curtain; Shopping Mall Fire; Evacuation; FDS; PyroSim.

\section{INTRODUCTION}

Fire hazard in Bangladesh, especially in urban areas like Dhaka city, is unfortunately a common occurrence. Being one of the mostly populated cities in the world, fire incidents might become a catastrophic disaster within a short period. Confining fire induced heat and smoke within the source, in case of a fire hazard, even if momentarily, can provide precious time to evacuees. Confining flame propagation after fire initiation by obstructing the fluid motion with fire doors, fire screens and other technologies is a suitable option to ensure safe evacuation before fire response units take control of the situation. Air curtains can be a viable alternative to places where solid obstructions to confine fire are nonimplementable, like road tunnels and shopping malls as the curtain jet can create an aerodynamic sealing between fire source and outside. And research suggests, air curtains are able to confine heat and mass transfer in case of tunnel fire, building fire and shopping mall fire [1-5]. Moreover, when implemented with air conditioning system, air curtain increases the thermal efficiency of the system and reduce cost and pollution, initiating a step towards the global call of green technologies [6,7].

Commercial spaces, like informal shopping malls are more prone to devastation from fire hazards than other areas as at any time substantial number of people gathered in those spaces. And, alarmingly at least $17 \%$ of fire incidents of Bangladesh are shopping mall fires [8]. Despite this high occurrence of fire incidents, only $4 \%$ shopping malls in the country meets safety standards, according to Bangladesh Fire Service and Civil Defense Authority (BFSCDA) [9]. Fig. 1 shows the present safety standard scenario of shopping malls of Bangladesh, where a handful of shopping malls in Dhaka city, the capital city of Bangladesh, and no shopping malls of Chattogram, the second largest city of Bangladesh, meets the safety standards.
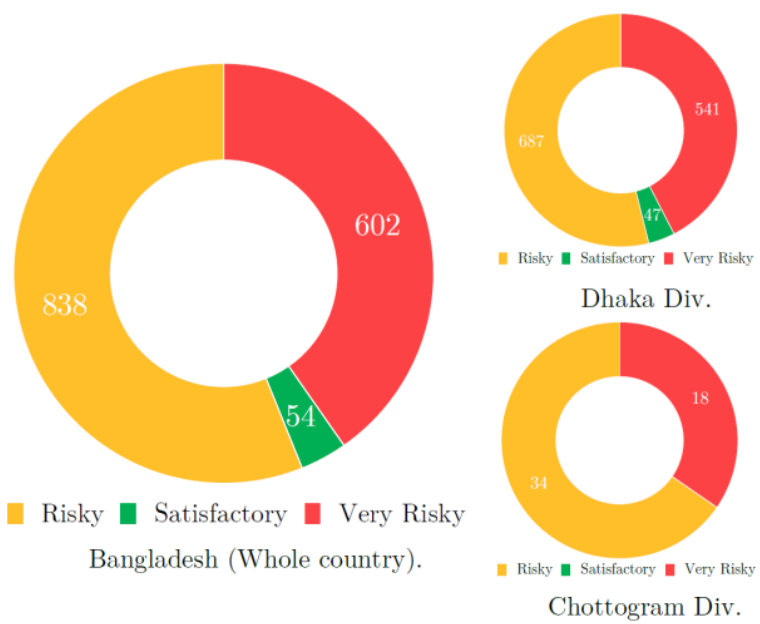

Fig. 1. Fire safety scenario of shopping malls in Bangladesh [9]. About $96 \%$ of the shopping malls in the country are deemed as 'risky' or 'very risky'.

The informal shopping malls, or informal architecture in general, means the establishments that have been adapted by the building owners and inhabitants to meet their environmental and functional necessities rather than by a holistic planning. The local cultural, economic, social and environmental factors play a large role in determining the characteristics of these informal architectures. In case of informal shopping malls in Bangladesh as shown in Fig. 2, the main features include many numbers of small-to-medium sized stores, narrow hallways, and maximization of the frontal road-side area of the buildings to attract shoppers.

A survey conducted on the informal shopping malls of Dhaka city, suggests most of the shops host compact stackings of high-density fuel loads, with products generally stored up to the ceiling of the shop, as can be seen from Fig. 3. During the survey it was observed 


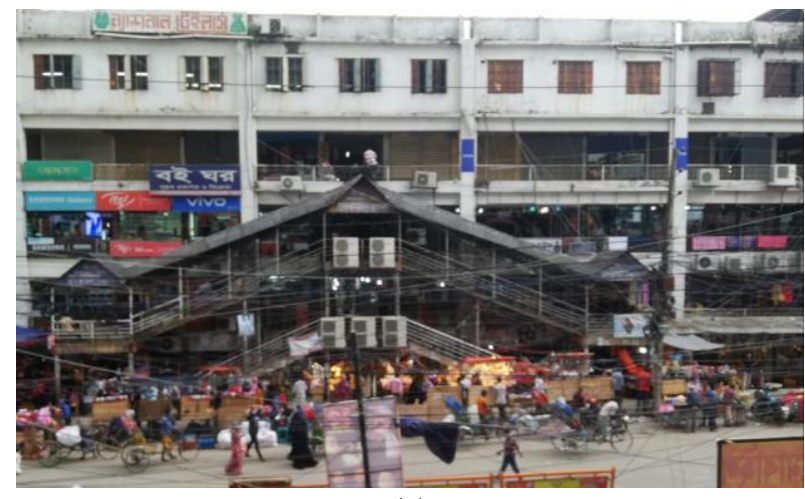

(a)

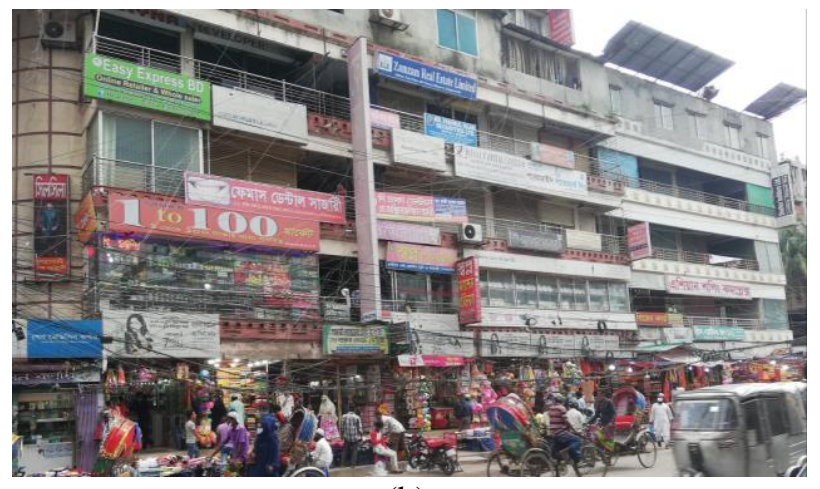

(b)

Fig. 2. Photographs of two informal shopping malls in the Dhaka city. There are many such shopping malls across the country.

that most of the shopping malls have minimal or no firefighting equipment, poor attention to fire safety standards, and critical evacuation areas of the malls were sometimes blocked with product stacks. These factors might have sinister consequences in otherwise avoidable situation during a fire incident. And during the survey it was also observed that, most of the shop owners of these informal shopping malls use split type air conditioning system for providing comfort to customers and by turn increase business opportunities. Thus, air curtain at shop door might be beneficial in both fire safety and economic perspective. And a systematic reduction of product quantity and orientation of those products inside the shops to limit the fire propagation during such fire incidents, might prove to be fruitful from evacuation perspective. This study numerically investigates air curtain performance in confining fire and smoke in clothing stores of informal shopping malls of Bangladesh in case of a fire incident, with different fuel orientations inside fire source store.

\section{METHODOLOGY}

\subsection{Fire Dynamics Simulator (FDS)}

To conduct the numerical analysis, the present study relies on Fire Dynamics Simulator FDS, (version 6.7.0 released on June 20, 2018). FDS is developed by the National Institute of Standards and Technology (NIST), Maryland, United States, a Large Eddy Simulation (LES) code widely used for fire simulation. PyroSim (version 2018.3.1210), a graphical user interface (GUI) for FDS, from Thunderhead Engineering was used for modelling the computational geometry in FDS. The Navier-Stokes equations were solved with low Mach number approximation in FDS, which is suitable for low speed,

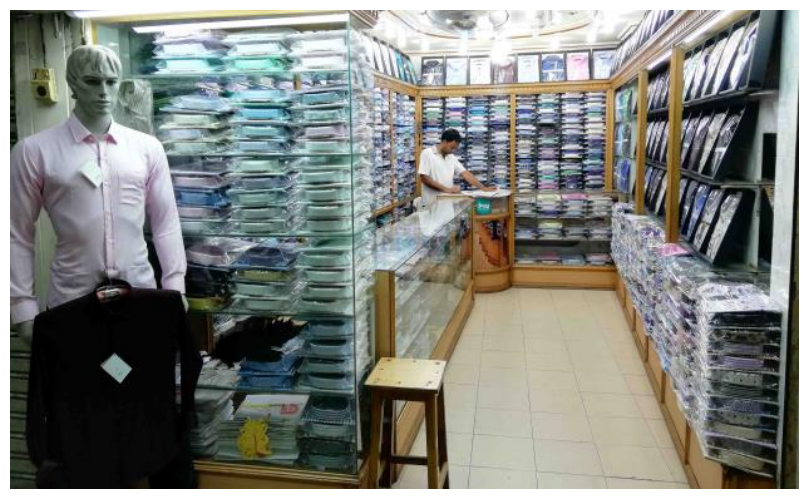

(a)

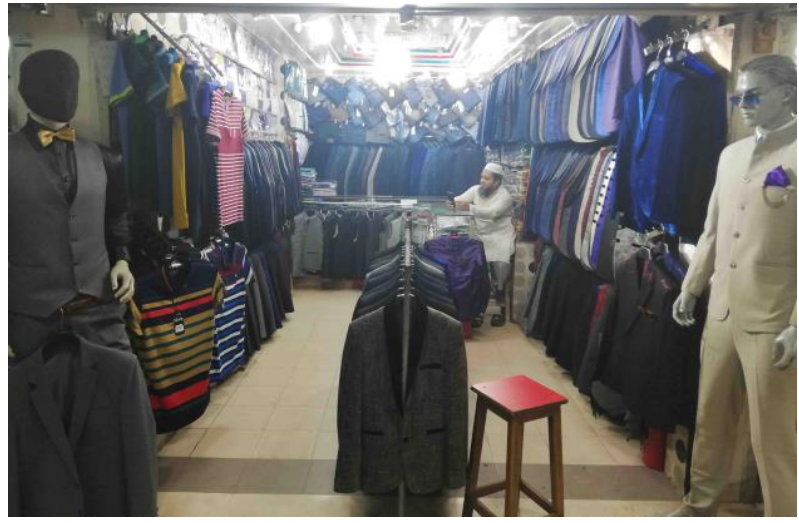

(b)

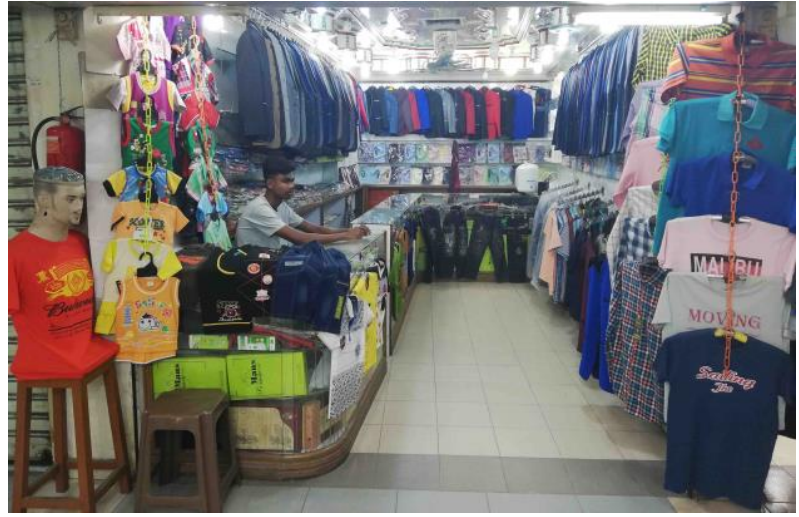

(c)

Fig. 3. Photographs of clothing stores in informal shopping malls of Dhaka city showing different fuel orientations and high-density fuel loads stored nearly up to the ceiling (photos were taken with permission during the field survey).

thermal convective processes like fire. The benefit of low Mach number approximation is that, it filters out acoustic waves and allows large variations in temperature and density. In FDS, LES handles turbulence modelling where large eddies of turbulent flow are computed in full detail. Equation (1) is the LES momentum equation with subgrid-scale (SGS) stress and mass-weighted Favre filter. From version 6.7.0 for computing the turbulent viscosity $\mu_{t}$, FDS uses a variation of Deardorff's model presented in equation (2).

$$
\begin{aligned}
& \frac{\partial \bar{\rho} \tilde{u_{l}}}{\partial t}+\frac{\partial}{\partial x_{j}}\left(\bar{\rho} \tilde{u_{\imath}} \widetilde{u_{\jmath}}\right) \\
& =-\frac{\partial \bar{\rho}}{\partial x_{i}}-\frac{\partial \overline{\tau_{l \jmath}}}{\partial x_{j}}-\frac{\partial \tau_{i j}^{s g s}}{\partial x_{j}}+\bar{\rho} g_{i}+\overline{f_{d, l}}+\overline{\dot{m}_{b}^{\prime \prime \prime}} \widetilde{u_{b, l}}
\end{aligned}
$$




$$
\begin{gathered}
\mu_{t}=\rho C_{v} \Delta \sqrt{k_{s g s}} \\
k_{s g s}=\frac{1}{2}\left((\bar{u}-\hat{\bar{u}})^{2}+(\bar{v}-\hat{\bar{v}})^{2}+(\bar{w}-\widehat{\bar{w}})^{2}\right) \\
k_{t}=\frac{\mu_{t} c_{p}}{P r_{t}} \\
(\rho D)_{t}=\frac{\mu_{t}}{S c_{t}}
\end{gathered}
$$

Constant turbulent Prandtl number $\mathrm{Pr}_{t}$ and constant turbulent Schmidt number $\mathrm{Sc}_{t}$ are used to express the thermal conductivity $k_{t}$, and mass diffusivity $(\rho D)_{t}$, in relation to the turbulent viscosity within the solver.

\subsection{Validation of the numerical model}

The combustion properties of clothing store are taken from a highly germane experimental work [10], by reproducing an ISO-9705 compatible room with different apparel items as fuel. Four different mesh sizes, Coarse, Moderate, Fine and Finer, were investigated to obtain a suitable case where computational time and resolution of results both reach acceptable limits. A non-dimensional expression $D^{*} / d x$, suggested by FDS user manual was used to define different mesh types in the model. The characteristic fire diameter $D^{*}$ is presented in equation (6).

$$
D^{*}=\left(\frac{\dot{Q}}{\rho_{\infty} c_{\infty} T_{\infty} \sqrt{g}}\right)^{\frac{2}{5}}
$$

Here, $\rho_{\infty}, c_{\infty}, T_{\infty}$ are the ambient density, specific heat, and temperature, and $\dot{Q}$ is the total heat release rate of the fire. The resulted $D * / d x$ values, cell size and element numbers are provided in Table 1. As suggested by previous works, the improvement in results was little after $D * / d x=10[11]$ as seen from Fig. 4.

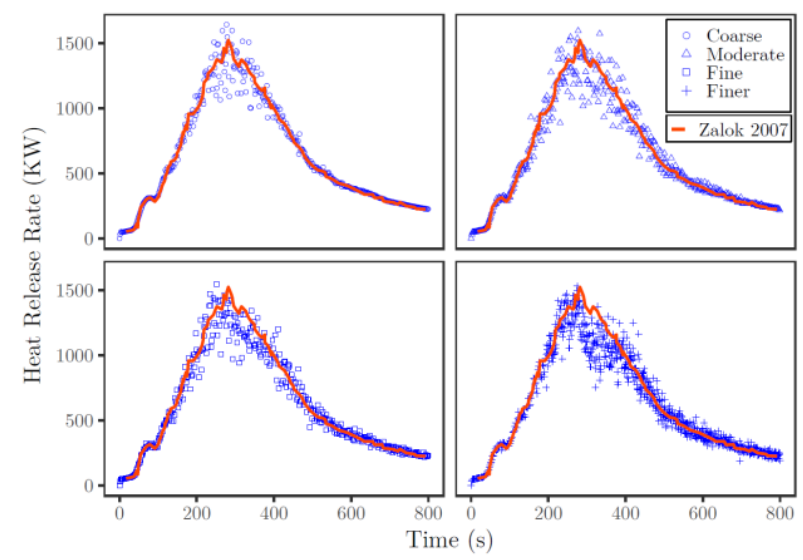

Fig. 4. Validation of numerical model and mesh sensitivity analysis with experimental works [10].

Table 1. Outline of the mesh sensitivity analysis.

\begin{tabular}{llll}
\hline \hline Mesh & D*/dx & Cell Size $(\mathrm{cm})$ & Elements \\
\hline Coarse & 4 & 28.5 & 768 \\
Moderate & 10 & 11.36 & 18432 \\
Fine & 16 & 7.1 & 64800 \\
Finer & 25 & 4.5 & 218700 \\
\hline \hline
\end{tabular}

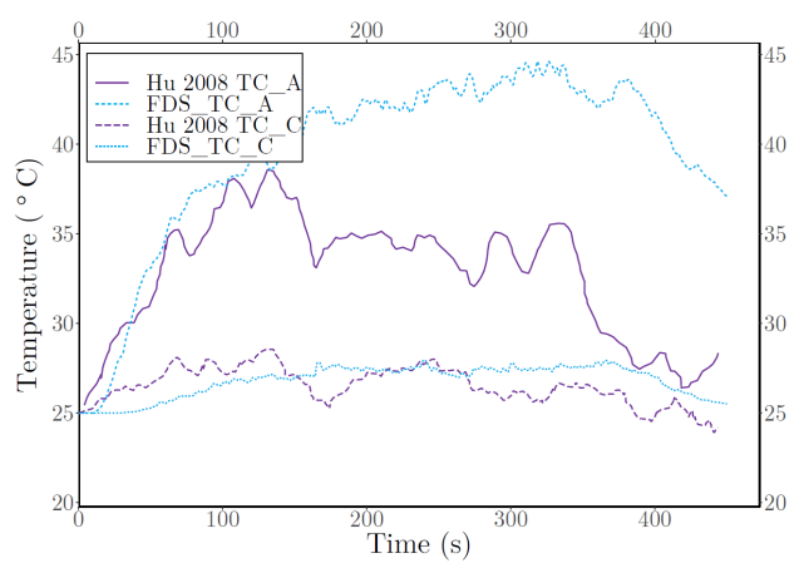

Fig. 5. Validation of experimental work for air curtain velocity of $3 \mathrm{~m} / \mathrm{s}$ [1].

The modelling of air curtain against fire in FDS was validated by reproducing another experimental work with tunnel fire [1]. Fig. 5 shows the temperature profile for before and after air curtain for experimental and FDS results and they are in well agreement within the acceptable limit.

\subsection{Numerical model from survey data}

During the survey on clothing stores, three general product arrangements were seen. Firstly, folded cloths stored on top of another in vertical direction named as 'Stacks' in this study. And, then cloths stored with hanger stored side by side in horizontal direction named as 'Racks'. And lastly, top tier cloths or "hanging garments" stored side by side for maximum exposure to incoming customers, are designated as 'Display'. Each type was designed in PyroSim with different bulk densities to imitate the actual product distribution in shops of informal shopping malls in Dhaka city, as seen during the survey. Fig. 6 shows a visual representation of the product arrangements and their respective design in PyroSim for better understandings of the scenario. The computational geometry investigated in the present study had around $315 \mathrm{~m}^{2}$ floor area with two open boundaries on the side and one on the top as seen in Fig. 7.

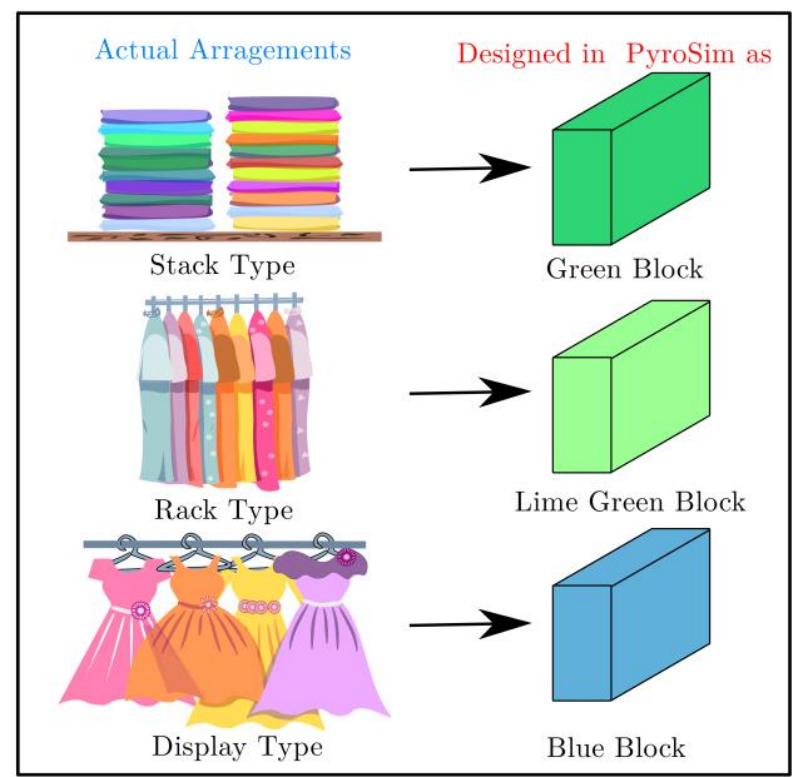

Fig. 6. Actual product arrangement in the clothing stores as observed during the survey and their respective representation in PyroSim. 


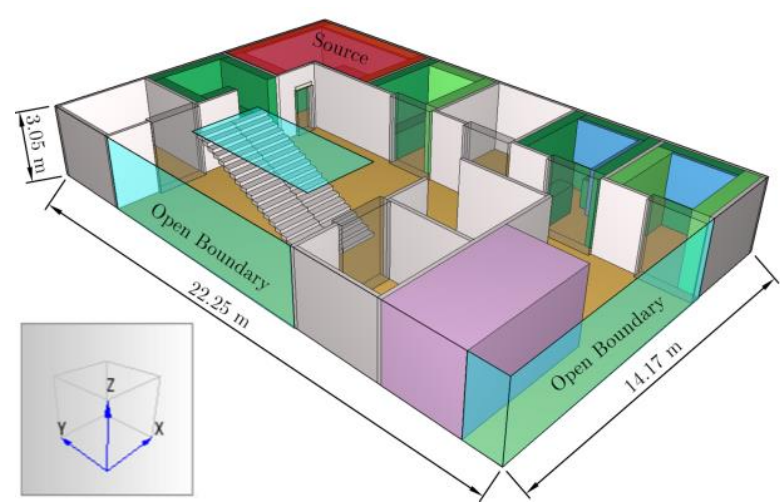

Fig. 7. Computational geometry in PyroSim showing relevant dimensions, source and open boundaries with actual clothing fuel distribution.

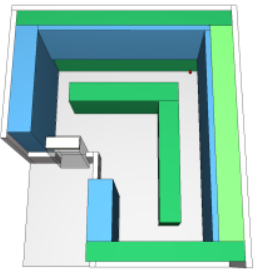

Actual Distribution

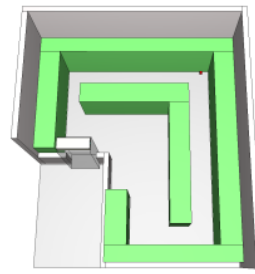

Grid Distribution

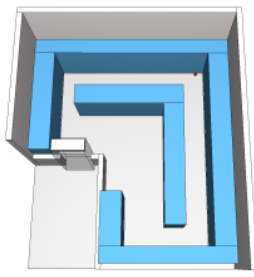

Display Distribution
Fig. 8. Fire source shop with different fuel distributions. Actual distribution as seen during the survey (left), standard Grid type distribution (middle), and assumed Display type distribution with extremely low clothing fuel load (right).

Two different mesh sizes were used, $D * / d x=15$ for source and $D * / d x=7.5$ for other portions of the geometry. The resulting cell size were cubes of $7.62 \times 7.62 \times 7.62 \mathrm{~cm}^{3}$ at the source and $15.24 \times 15.24 \times 15.24 \mathrm{~cm}^{3}$ at other regions, yielding a total of 523,560 mesh elements. The computational geometry was then designed for three different types of fuel orientation with varying fuel density and fuel distributions. Firstly the 'Actual Distribution' was designed by imitating the fuel arrangements and fuel distribution seen during the survey with all three arrangements 'Stacks', 'Racks' and 'Display', resulting an extremely high-density fuels oriented in a compact manner. Secondly 'Grid Type Distribution' was designed following the standard 'Grid layout' with 'Rack' type arrangements investigated by a relevant study to reduce the fuel to only $20 \%$ of the 'Actual' distribution [12]. Lastly to reduce the clothing fuel load to a minimum, only $5 \%$ of 'Actual' fuel content, a conceptual 'Display Type Distribution' was designed on 'Grid layout' with 'Display' type fuel arrangements. The fuels were stored up to $1.52 \mathrm{~m}$ for 'Grid' and 'Display' type distributions were as in 'Actual' distribution it was up to $3.04 \mathrm{~m}$ as shop owners generally stored products up to ceiling height. PyroSim models of source shop with different fuel distributions are shown in Fig. 8.

\section{RESULTS AND DISCUSSION}

The fire and smoke propagation, in case of a fire incident at the source shop, with different types of clothing fuel orientation, can be seen from Fig. 9. At 200s, the shop inside for 'Actual Distribution' is not visible at all due to a thick smoke accumulated at ceiling, where for 'Grid' and 'Display' type the smoke is a bit less dense at 200 s retaining some visibility inside the source. But as this

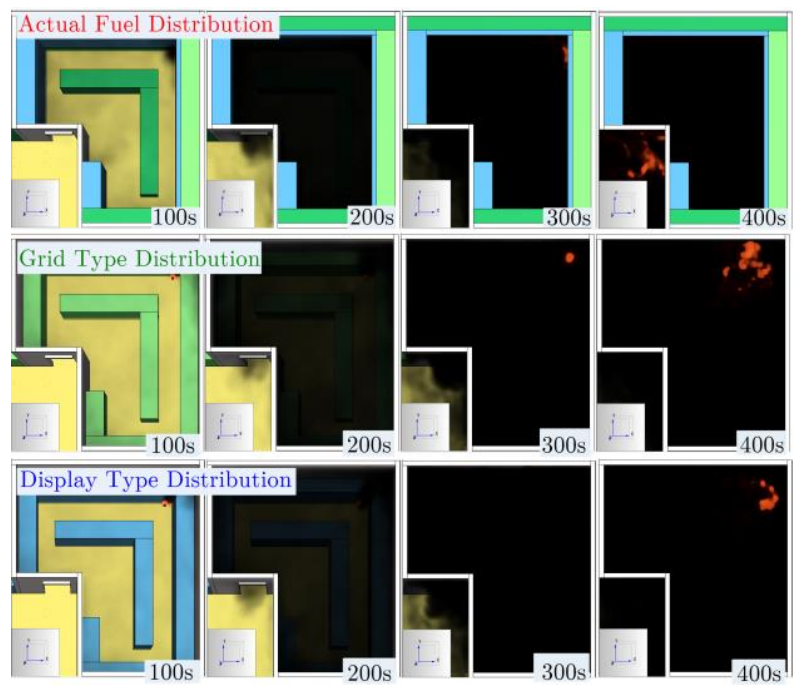

Fig. 9. Snapshots of fire and smoke propagation through the fire source shop for different fuel orientations at $100 \mathrm{~s}, 200 \mathrm{~s}, 300 \mathrm{~s}$ and $400 \mathrm{~s}$ of simulation time (from left to right) from PyroSim. On top for 'Actual fuel distribution', in middle for 'Grid type distribution' and at bottom for 'Display type distribution'.

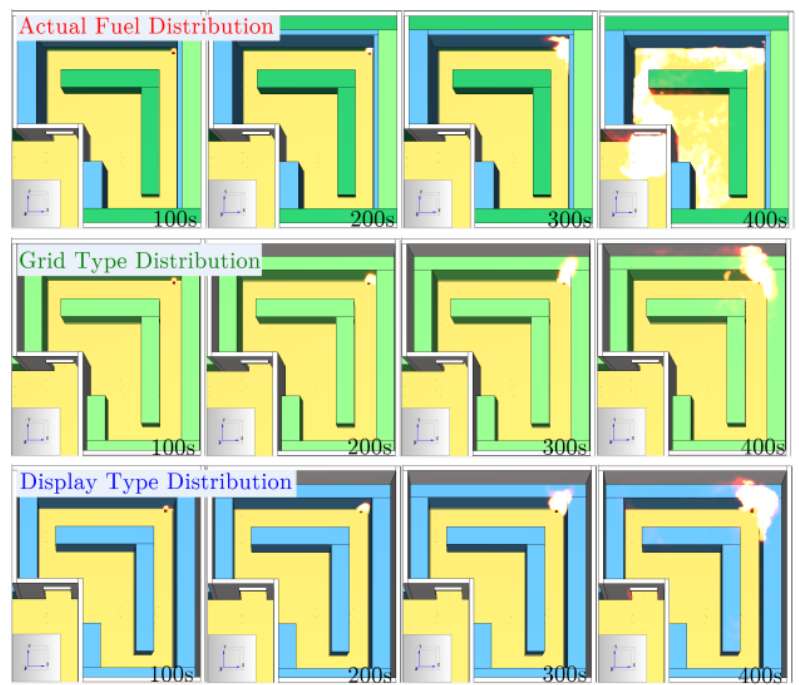

Fig. 10. Snapshots of fire propagation only (for better visualization) through the fire source shop for different fuel orientations at 100s, 200s, 300s and 400s. On top for 'Actual fuel distribution', in middle for 'Grid type distribution' and at bottom for 'Display type distribution'.

thick smoke continued to produce as combustion progress, the flame propagation is not perceptible at any instances of Fig. 8, thus, Fig. 10 is plotted for similar conditions but without the soot particles from FDS calculation. From Fig. 10, it is evident that, the flame propagation for 'Actual' distribution is more threatening than the 'Grid' and 'Display' type distribution, as at around $400 \mathrm{~s}$, the flame engulfed the total source and burning violently at the source door for 'Actual' distribution case. Interestingly for 'Grid' and 'Display' type distribution the flame propagation scenarios were somewhat similar. This similarity was again seen in heat release rate (HRR) curves of Fig. 11. With high fuel density of 'Actual' distribution burning occurs violently and after 600 s of simulation time the total heat released is extremely higher than the heat released by 'Grid' and 'Display' type distribution. And, the total heat released 


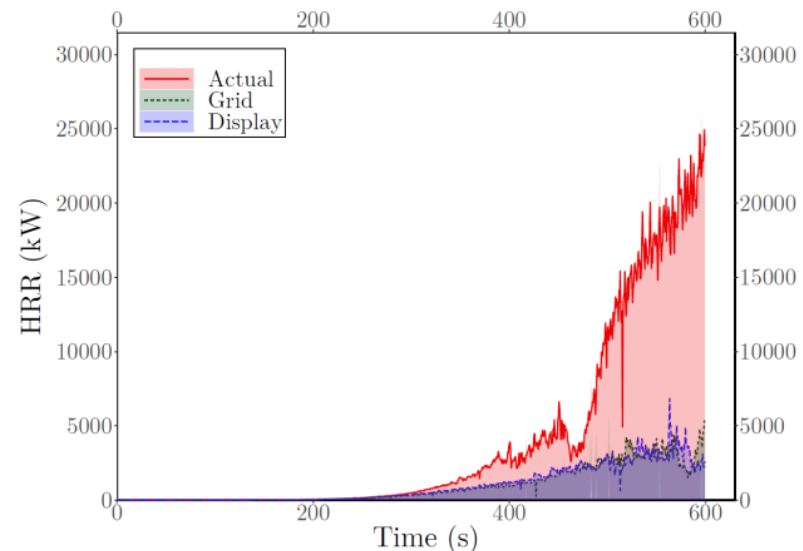

Fig. 11. Comparison of heat release rate (HRR) during as fire event at source shop for 'Actual', 'Grid' and

'Display' type clothing fuel orientation.

by 'Grid' and 'Display' type fuel distribution were only $24 \%$ of that of the 'Actual' distribution. Again, the heat release rate curve and total heat released for 'Grid' type having $20 \%$ fuel load of 'Actual' distribution, and 'Display' type having 5\% fuel load of 'Actual' distribution, closely followed each other. So, even if the fuel load is reduced to only $5 \%$ in 'Display' type distribution from the $20 \%$ value of 'Grid' distribution, flame propagation and heat release rate were virtually unchanged. This was due to the fact that, with extremely high ratio of surface area to density, the 'Display' type distribution was favoring the combustion process and thus, provide no improvement on fire behavior over 'Grid' type distribution.

The temperature profiles at $2.9 \mathrm{~m}$ height from the floor and at $1.14 \mathrm{~m}$ distance after the air curtain were plotted for no air curtain case, air curtain discharged against 'Actual' fuel load case, air curtain discharged against 'Grid' type fuel load case, and air curtain discharged against 'Display' type fuel load case, in Fig. 12. The horizontal line represents $80^{\circ} \mathrm{C}$, the human tenability limit for temperature [13]. The temperature profile for 'Grid' type distribution, the green curve of Fig. 12, crossed tenability limit at around $421 \mathrm{~s}$, significantly later than other fuel distribution types, thus ensuring increased safe evacuation time for the evacuees, again demonstrating superiority of 'Grid' type distribution over other distribution types.

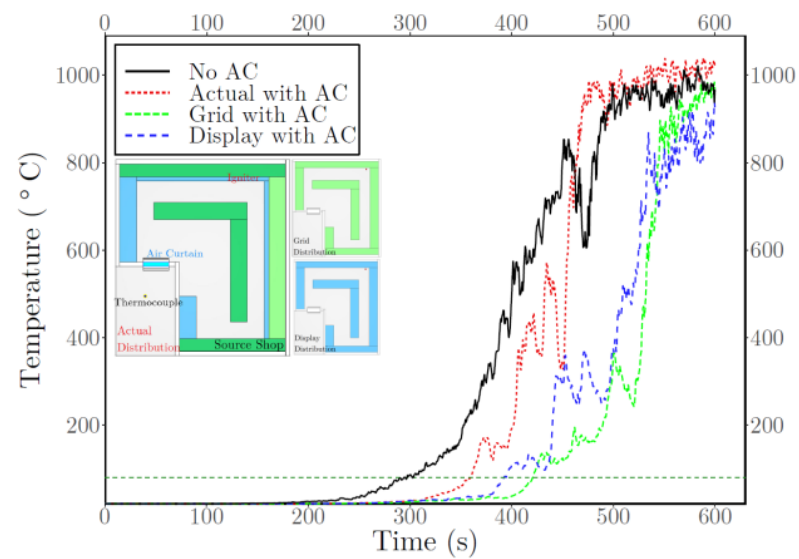

Fig. 12. Temperature profile at $1.14 \mathrm{~m}$ distance after air curtain, in case of a fire event at source shop, for 'Actual', 'Grid' and 'Display' type clothing fuel orientation

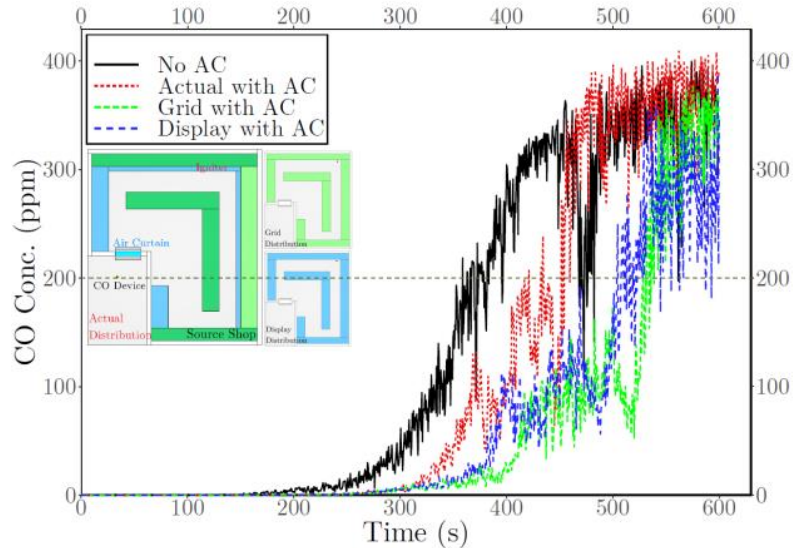

Fig. 13. Carbon monoxide concentration at $0.84 \mathrm{~m}$ distance after air curtain, in case of a fire event at source shop, for 'Actual', 'Grid' and 'Display' type clothing fuel orientation.

Fig. 13 shows the carbon monoxide $(\mathrm{CO})$ concentration at $2.9 \mathrm{~m}$ height for 'Actual', 'Grid' and 'Display' type clothing fuel orientation with air curtain discharged, and no curtain condition, at a distance of $0.84 \mathrm{~m}$ from the air curtain (outside the source). The horizontal line here represents the $200 \mathrm{ppm} \mathrm{CO}$ concentration, exposure to this concentration for 2 to 3 hours will result in loss of judgement for the evacuees [14]. The 'Grid' type distribution again provided the best-case scenario in case of limiting CO concentration over the other two fuel distributions.

The comparative analysis between each fuel distribution type is summarized in Fig. 14. The reported air curtain effectiveness here is calculated with equation (7), and defined as the fraction of heat transfer through the door that is confined by the air curtain jet, compared to no air curtain condition.

$$
E=1-\left(Q_{a} / Q_{\text {open }}\right)
$$

Here $Q_{a}$ is the amount of heat transfer through the door against the air curtain jet, and $Q_{\text {open }}$ is the amount of heat transfer through the door without the air curtain jet. While the air curtain effectiveness is similar for 'Actual' and 'Grid' distribution, the increase in time needed for the flame to spread onto the hallway is $50 \mathrm{~s}$ longer in case of 'Grid' distribution and from evacuation perspective this increment in safety egress time is invaluable. At a first glance, the 'Display' type distribution is seemed to had a higher effectiveness than other fuel orientations, but a closer look at the total heat released ratio, the ratio of heat released with and without air curtain discharged, and period of air curtain effectiveness provided a different viewpoint. With the introduction of air curtain jet inside the source, rate of combustion inside the source is enhanced for fuel distributions with low thermal inertia and thus the increment in total heat released for 'Grid' and 'Display' type distributions. And, about $150 \%$ increment in total heat released for 'Grid' type distribution and about $130 \%$ for 'Display' type distribution. Also, air curtain was effective for $410 \mathrm{~s}$ for for 'Grid' type distribution, i.e., 15 s longer than 'Display' type distribution. Thus, air curtain was effective at higher heat release rate and for longer period while discharged against the 'Grid' type distribution and thus, this contrast 


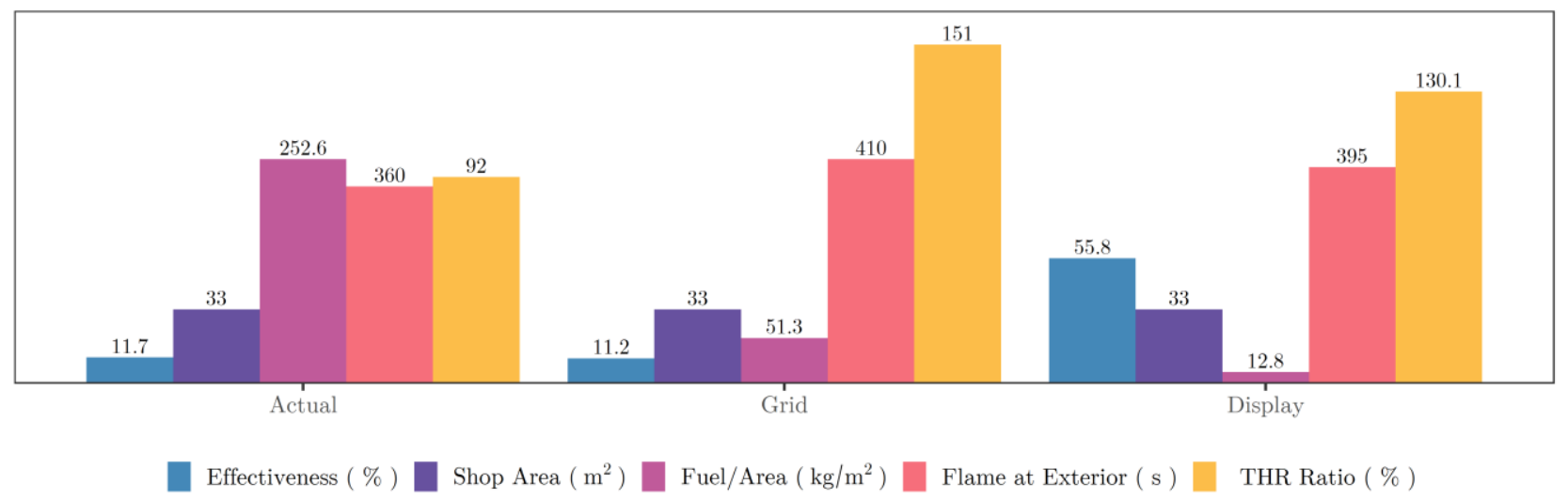

Fig. 14. Comparison of air curtain effectiveness, fuel per unit shop area, flame spread time and total heat released ratio among different types of fuel orientation.

in numerical values of air curtain effectiveness. Hence, this comparative analysis solidifies the claimed advantage of 'Grid' type distribution over other fuel distribution types.

Although the detrimental effect of vertically stored fuel during a fire event is well known, most of the shop owners tend to stack the clothing products vertically, nearly up to the ceiling in many cases, as seen during the survey. Thus, another fuel distribution with standard 'Grid' layout and 'Rack' type fuel arrangements designed up to $3.04 \mathrm{~m}$ height (from the floor) was investigated and compared with the 'Grid' type fuel distribution, as presented in Fig. 15, to pin point the negative effect in context of informal shopping malls in Bangladesh. While only gaining $75 \%$ increment in the storage capacity inside the shop, air curtain (when discharged) had nearly $30 \%$ reduction in effectiveness against this new distribution, and flame spread to the hallway was 77 s $(18 \%)$ earlier, indicating reduction in safe evacuation time. Due to this damaging effect on

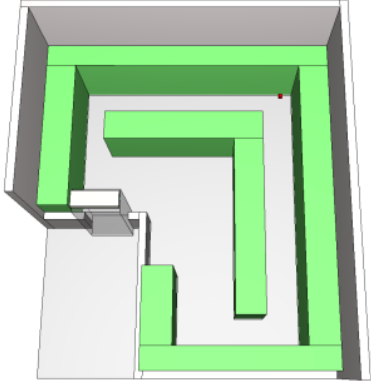

A. Fuel Stored up to $1.52 \mathrm{~m}$

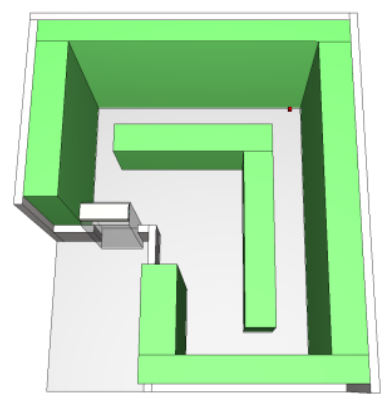

B. Fuel Stored up to $3.04 \mathrm{~m}$

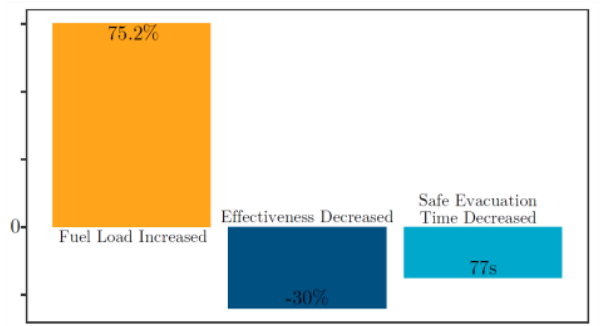

Comparative Analysis between A and B

Fig. 15. Comparison between 'Grid type fuel distribution' and another 'Grid layout' with fuel stored up to the ceiling ( $3.04 \mathrm{~m}$ ) of the shop. Both the loss of air curtain effectiveness and safe evacuation time were compared with the increased amount of the fuel that can be stored in this orientation. otherwise an advantageous fuel distribution (the Grid type), vertical storing of clothing products is highly discouraged in real life scenarios.

\section{CONCLUSION}

A numerical study has been carried out on the effect of fuel orientation on air curtain effectiveness in confining flame and smoke propagation in informal shopping malls of Bangladesh in case of clothing store fire. Three fuel packages, three types of distribution of those fuel packages and two storage height were investigated to obtain a favorable configuration from the perspective of safe occupant evacuation. The results indicate that reducing the fuel load to $20 \%$ of the actual distribution with 'Grid' type fuel distribution improves the fire spread behavior from evacuation perspective and increase the effectiveness of air curtains. Further fuel load reduction to $5 \%$ with 'Display' type fuel distribution has no visible improvement over 'Grid' type fuel distribution due to the easier combustion for this distribution. Storing fuel vertically at large heights proved to be fatal even with the most suitable fuel arrangements and discouraged in real life applications. Rearrangement of 'Grid' type fuel distribution to further increased the air curtain effectiveness and period of effectiveness can be pursued in future endeavors.

\section{Acknowledgements}

The authors would like to express their gratitude and appreciation to Thunderhead Engineering for the academic license of PyroSim software.

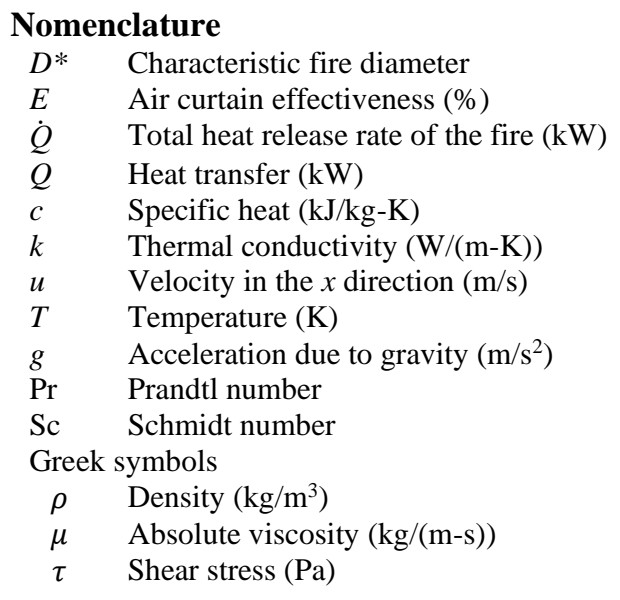




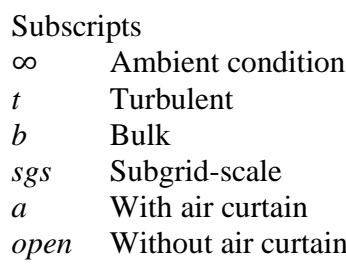

\section{REFERENCES}

[1] L.H. Hu, J.W. Zhou, R. Huo, W. Peng, H.B. Wang, Confinement of fire-induced smoke and carbon monoxide transportation by air curtain in channels, Journal of hazardous materials. 156 (2010) 327-334.

[2] J.C. Elicer-Cortés, R. Demarco, A. Valencia, M. Pavageau, Heat confinement in tunnels between two doublestream twinjet air curtains, International Communications in Heat and Mass Transfer. 36 (2009) 438-444.

[3] N. Luo, A. Li, R. Gao, Z. Tian, W. Zhang, S. Mei, L. Feng, P. Ma, An experiment and simulation of smoke confinement and exhaust efficiency utilizing a modified Opposite Double-Jet Air Curtain, Safety science. 55 (2013) 17-25.

[4] L.X. Yu, F. Liu, T. Beji, M.C. Weng, B. Merci, Experimental study of the effectiveness of air curtains of variable width and injection angle to block fireinduced smoke in a tunnel configuration, International Journal of Thermal Sciences. 134 (2018) 13-26.

[5] M. A. M. S. Shoshe, M. A. Rahman, Effectiveness of Air Curtains as Thermal and Smoke Barrier Against High Gradients of Flow Parameters, Proceedings of the 5th World Congress on Mechanical, Chemical, and Material Engineering (MCM'19), Lisbon, Portugal, 2019.

[6] H. Farzaneh, Multiple Benefits Assessment of the Low Emission Development Strategies in Asian cities, Proceedings of International Exchange and Innovation Conference on Engineering \& Sciences (IEICES), Interdisciplinary Graduate School of Engineering Sciences, Kyushu University, Fukuoka City, Japan, 2019, pp. 15-16.

[7] M. Hassan, T.H. Rupam, W. Bin Habib, Green Building : An Emerging Technology for the Energy Crisis of Bangladesh, Proceedings of International Exchange and Innovation Conference on Engineering \& Sciences (IEICES), Interdisciplinary Graduate School of Engineering Sciences, Kyushu University, Fukuoka City, Japan, 2016.

[8] M.J. Alam, G.N. Baroi, Fire hazard categorization and risk assessment for dhaka city in gis framework, J. Civ. Eng.(IEB). 32 (2004) 35-45.

[9] BFSCDA Annual Fire Report, Technical Report 1, Bangladesh Fire Service and Civil Defense Authority. Dhaka, Bangladesh, 2019.

[10] E. Zalok, G. Hadjisophocleous, Characterizing of design fires for clothing stores, Proceedings of the 5th International Seminar on Fire and Explosion Hazards, Edinburgh, UK, 2007, pp. 328-337.

[11] R.J. McDermott, G.P. Forney, K. McGrattan, W.E Mell, Fire Dynamics Simulator Version 6: Complex Geometry, Embedded Meshes, and Quality Assessment, Proceedings of the V European Conference on Computational Fluid Dynamics ECCOMAS CFD 2010, Lisbon, Portugal, 2010.
[12] M. A. M. S. Shoshe, M. A. Rahman, Spread and Propagation of Generic Shopping Mall Fire of Bangladesh Under Different Scenarios, Proceedings on International Conference on Disaster Risk Management, Dhaka, Bangladesh, 2019, p. 641-648.

[13] NFPA 130, Standard for Fixed Guideway Transit and Passenger Rail Systems, National Fire Protection Association, 2017.

[14] M. Goldstein, Carbon monoxide poisoning, Journal of Emergency Nursing. 34 (2008) 538-542. 